\title{
A CONSCIENTIZAÇÃO COMO FATOR DE DESENVOLVIMENTO DA ATIVIDADE TURÍSTICA
}

Novos Olhares Sobre o Turismo

\author{
Milene Torelli Lapenta
}

Bacharel em Turismo pela Universidade de Marília - UNIMAR. Mestre em Turismo pelo Centro Universitário Ibero Americano UNIBERO. Professora universitária dos Cursos de Turismo com Ênfase em Hotelaria da Universidade do Oeste Paulista UNOESTE em Presidente Prudente e do Curso de Turismo da Faculdade de Ciências Gerenciais de Dracena - CESD.

\section{Resumo}

O presente artigo tem o objetivo de demostrar a falta de conscientização da comunidade de uma localidade e do turista em relação aos benefícios que a atividade turística pode proporcionar em um destino. Para tanto, foram utilizadas pesquisas com jovens universitários para inventariar o grau de consciência e conhecimento dos entrevistados em relação ao desenvolvimento do Turismo em uma localidade. A primeira parte da pesquisa tratou de diagnosticar, por meio de questionários, a existência ou não do conhecimento, por parte de jovens universitários, sobre os benefícios do turismo. Os resultados da primeira parte da pesquisa apontam que a maioria das pessoas ainda não tem conhecimento sobre a atividade turística embora acreditem que possa ser um caminho para o desenvolvimento de municípios com potencialidades turísticas.

Palavras - chave: conscientização, desenvolvimento, projetos e benefícios.

\section{THE CONSCIOUSNESS AS A FACTOR OF THE TOURISM ACTIVITY DEVELOPMENT}

\begin{abstract}
This article aims to demonstrate the importance to elaborate projects that objective to make the community and tourists conscious of the importance in developing the Tourism and the benefits that this activity may provide. So, researches were made with young college students to register the enterviewed level of consciousness and knowledge in relation to the tourism development in some place. The first part of the research diagnoses, by making questions, the existence or non-existence of the knowledge mans, among young high school students, about the benefits of turism. The result was most people don't have knowledge about the tourism activity yet, development of the towns with tourism potency.

Keywords: consciouness, development, projects, benefits.
\end{abstract}




\section{Introdução}

O turismo é uma atividade que tem se destacado nos últimos anos, devido seu envolvimento com diversos segmentos sociais, econômicos e culturais de uma localidade, além de gerar empregos diretos e indiretos, fomentando o desenvolvimento local.

À partir de um planejamento de ações, é possível explorar sustentavelmente uma localidade, tornando-a atrativa para os turistas e estruturalmente equipada para a comunidade local. Investimentos são indispensáveis em relação à infra-estrutura básica como água, energia elétrica, saneamento, calçadas, sarjetas, guias; infra-estrutura turística como meios de hospedagem, transportes, agências de viagem e turismo, restaurantes, lanchonetes, entretenimento em geral; equipamentos de apoio como casas bancárias e de câmbio, postos de gasolina, postos de saúde, entre outros.

O turismo é uma atividade que tem grande importância no desenvolvimento socioeconômico. É uma atividade que possui grande poder de redistribuição espacial de renda. É uma atividade que é intensiva em mão-de-obra, podendo contribuir para o grande problema da sociedade moderna que é o desemprego estrutural. O turismo, ainda, tem papel muito importante na conservação do meio natural (...) e no desenvolvimento cultural das comunidades (IGNARRA, 2002, p. 61).

A organização desses segmentos que compõem a oferta complementar de uma localidade é indispensável, já que não é possível trazer turistas sem a existência de uma estrutura mínima para receber os visitantes.

O aumento do "tempo livre"; o desenvolvimento dos transportes; a segmentação do mercado turístico focalizado na preferência das pessoas; o desenvolvimento tecnológico; conversão de elementos das localidades para produtos turísticos; diminuição do numero de pessoas nas famílias; a renovação do mercado e outros tantos fatores possibilitam o aumento da demanda turística e desenvolvimento das localidades.

Hoje, o turismo é a terceira maior atividade do mundo, e mesmo assim não recebe a devida importância que merece como afirma 0 autor Adyr Balastreri Rodrigues (2002):

Atividade complexa, de importância
crescente e de significativo potencial
de impacto (positivo e negativo) sobre
as relações sociais e o ambiente, o
Turismo merece, por isso, mais que um
lugar subalterno no contexto da
reflexão teórica
desenvolvimento (p.15).

Devido às tendências mercadológicas atuais, aos benefícios e a não valorização da atividade turística, sentiu-se a necessidade de desenvolver um projeto que visa a quebra do preconceito com o mercado turístico e com os profissionais envolvidos.

Para o desenvolvimento de um Turismo sustentável, é de extrema importância a participação da comunidade para que haja um entendimento maior dessas pessoas na atividade. A falta de conscientização das comunidades sobre os benefícios que 0 turismo pode proporcionar a uma localidade, ainda é um entrave para o crescimento da atividade dentro do país.

\section{A Necessidade do Conhecimento}

Infelizmente a visão que a maioria das pessoas têm em relação a atividade é somente 
focada nas viagens, sem se preocupar na organização e planejamento que envolvem tais atividades.

Nos bastidores das viagens, há também muito trabalho, organização, planejamento e estudos para que nada saia errado e para que o turista possa desfrutar de momentos de extrema tranqüilidade.

Como professora universitária em Cursos de Turismo da região do Oeste Paulista, senti que os alunos também tinham essa mesma percepção, ou seja, as pessoas não têm conhecimento dos benefícios que o Turismo pode proporcionar a uma localidade, quando explorado da maneira correta. Então, nada mais justo e propício que um bacharel e futuros profissionais da área se unissem para dar início a um trabalho tentando mudar esse cenário.

\section{Material e Métodos}

Por meio dessa vontade mútua de esclarecimento e conscientização da população sobre os benefícios que o Turismo pode trazer para uma localidade, surgiu a idéia da elaboração de um projeto intitulado "Novos olhares sobre o Turismo".

O projeto teve início no $1^{\circ}$ Semestre do ano de 2006, com a participação de 20 alunos que cursavam o $3^{\circ}$ Termo da Faculdade de Turismo com Ênfase em Hotelaria da Universidade do Oeste Paulista - UNOESTE, agregando valor em trabalhos desenvolvidos em sala de aula enquanto era ministrada a disciplina de Teoria e Técnica do Turismo II.

Para viabilizar essa idéia, o projeto "Novos Olhares sobre o Turismo", foi dividido em duas partes: a primeira parte, já concluída, consistia em aprofundar a pesquisa bibliográfica para dar embasamento científico ao trabalho. Os alunos foram divididos em grupos menores, proporcionando um trabalho de melhor qualidade. Nessa etapa foi elaborado um cronograma das atividades que seriam desenvolvidas, dando ritmo a pesquisa. Periodicamente foram realizadas conferências para acompanhar o desenvolvimento das atividades, dentro dos prazos estabelecidos.

Esse trabalho durou oito semanas, já que é a base estrutural para o desenvolvimento de ações futuras, necessitando estar bem fundamentadas teoricamente.

Para concluir a primeira etapa do projeto, foi elaborado um questionário que seria aplicado, inicialmente, com os alunos dos últimos termos dos Cursos noturnos do campus II da UNOESTE, conforma mostra a Tabela 1.

A escolha do público-alvo teve o embasamento de que esses alunos já teriam amadurecido seus conhecimentos gerais, por estarem quase saindo da faculdade. Este questionário tinha como objetivo principal mensurar o nível de conscientização que essa amostra populacional tinha sobre o Turismo.

A segunda etapa do projeto (em elaboração) consistirá na elaboração de materiais informativos sobre a importância da conscientização para o desenvolvimento do Turismo em uma localidade, e quais os benefícios sociais, econômicos e culturais que a atividade poderá trazer para o município e região. Este material será confeccionado em forma de cartilhas e serão distribuídas, inicialmente, nas escolas do ensino fundamental do município de Presidente Prudente. Esta distribuição será complementada com palestras informativas e explicativas, elaboradas pelos alunos da Faculdade de Turismo da Universidade do Oeste Paulista, envolvidos neste projeto. 
Esta etapa tem o objetivo de conscientizar as pessoas, desde jovens, sobre os benefícios que o seu município poderá ter planejando e organizando o turismo e qual é o seu papel, o papel do poder público, do poder privado e do profissional do Turismo.

Tabela 1 - Alunos envolvidos na pesquisa

\begin{tabular}{|c|c|}
\hline Curso & $\begin{array}{l}\text { Quantida } \\
\text { de de } \\
\text { alunos }\end{array}$ \\
\hline Alunos do Curso de Direito (10Termo) & 93 \\
\hline $\begin{array}{l}\text { Alunos do Curso de Administração } \\
\text { (8ºrmo) }\end{array}$ & 50 \\
\hline $\begin{array}{l}\text { Alunos do Curso de Ciências Contábeis } \\
\left(8^{\circ} \text { Termo) }\right.\end{array}$ & 09 \\
\hline $\begin{array}{l}\text { Alunos do Curso Superior de Tecnologia } \\
\text { de Gestão de Negócios ( } 4^{\circ} \text { Termo) }\end{array}$ & 14 \\
\hline $\begin{array}{l}\text { Alunos do Curso de Psicologia } \\
\left(10^{\circ} \text { Termo }\right)\end{array}$ & 16 \\
\hline $\begin{array}{l}\text { Alunos do Curso de Publicidade } \\
\text { ( } 8^{\circ} \text { Termo) }\end{array}$ & 03 \\
\hline $\begin{array}{l}\text { Alunos do Curso de Jornalismo } \\
\left(8^{\circ} \text { Termo) }\right.\end{array}$ & 05 \\
\hline $\begin{array}{l}\text { Alunos do Curso Superior de Tecnologia } \\
\text { de Música ( } 3^{\circ} \text { Termo) }\end{array}$ & 14 \\
\hline $\begin{array}{l}\text { Alunos do Curso Superior de Tecnologia } \\
\text { de Processos Químicos ( } 5^{\circ} \text { Termo) }\end{array}$ & 17 \\
\hline $\begin{array}{l}\text { Alunos do Curso de Sistemas de } \\
\text { Informação ( } 8^{\circ} \text { Termo) }\end{array}$ & 16 \\
\hline $\begin{array}{l}\text { Alunos do Curso de Tecnologia de Web } \\
\text { Designer (6ºTermo) }\end{array}$ & 15 \\
\hline $\begin{array}{l}\text { Alunos do Curso de Educação Física } \\
\text { (7ºTermo) }\end{array}$ & 39 \\
\hline $\begin{array}{l}\text { Alunos do Curso Superior de Tecnologia } \\
\text { de Designer de Ambientes ( } 3^{\circ} \text { Termo) }\end{array}$ & 15 \\
\hline $\begin{array}{l}\text { Alunos do Curso Superior de Tecnologia } \\
\text { de Conservação e Planejamento } \\
\text { Ambiental (5Termo) }\end{array}$ & 22 \\
\hline \multicolumn{2}{|c|}{$\begin{array}{l}\text { Total de Público a ser Atingido........................... } 328 \\
\text { alunos }\end{array}$} \\
\hline
\end{tabular}

\section{Resultados e Discussões}

Após a aplicação dos questionários, deu-se início a tabulação dos dados da pesquisa, e com o resultado seria possível saber qual o nível de conscientização que a nossa amostra possuía sobre o Turismo, contribuindo para a continuidade do projeto.

\section{Gráfico 1}

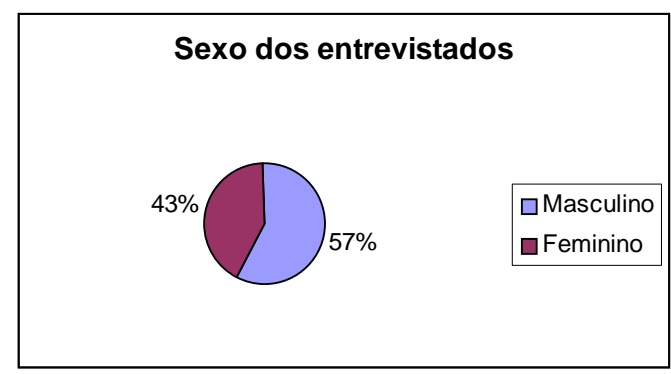

Gráfico 2

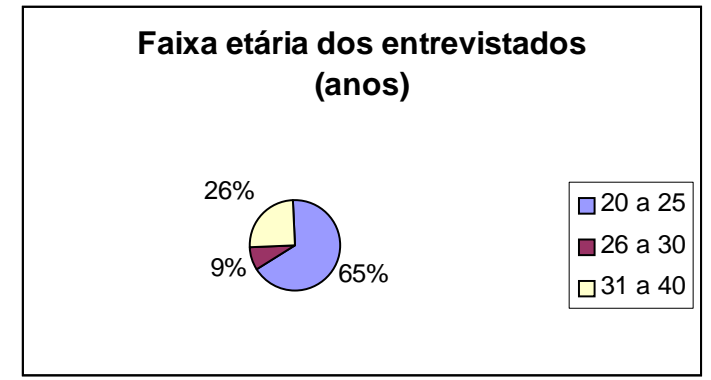

Gráfico 3

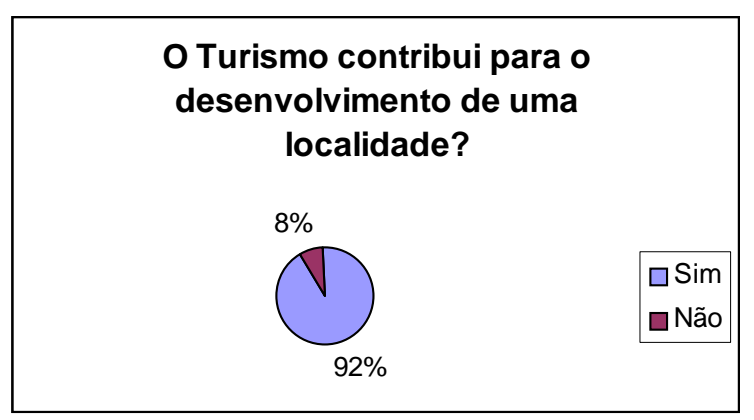

Nesta pergunta havia a possibilidade dos entrevistados exporem algumas justificativas referentes ao questionamento 
realizado. Os entrevistados acreditam que o turismo contribui para o desenvolvimento de uma localidade, pois aumenta a renda para o município; gera empregos diretos e indiretos; desenvolve econômica, social e culturalmente uma localidade, além de divulgar o município.

Ao serem questionados, os entrevistados complementaram suas respostas, ou seja, os entrevistados acreditam que é importante o Turismólogo estar presente no desenvolvimento sustentável de uma localidade por ser mais capacitado; ter conhecimento específico e a longo prazo.

\section{Gráfico 4}

Tempo de Permanência no Local (dias)

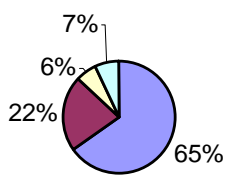

Gráfico 5

\section{O que o Turismo representa para o entrevistado}

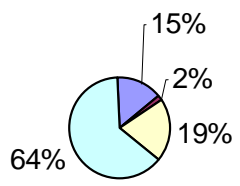

\section{Gráfico 6}

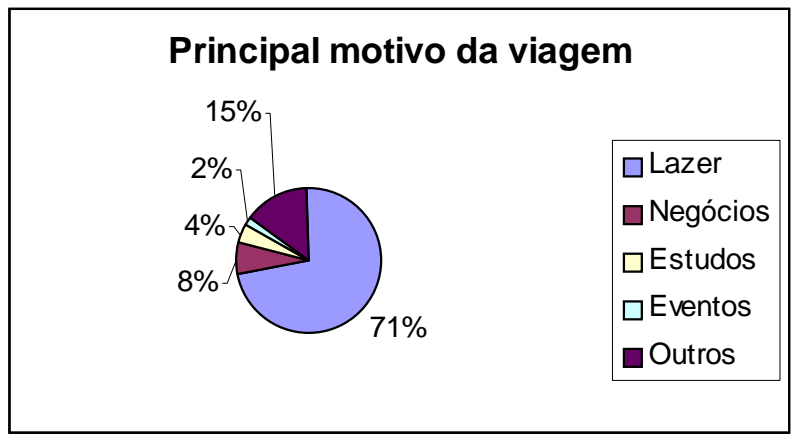

\section{Conclusão}

Após análise dos dados obtidos através da pesquisa, foi possível concluir que o nosso público é em sua maioria masculino com idade entre 20 e 25 anos, em suas viagens costuma permanecer no local de um a sete dias, tendo como principal motivo as viagens de lazer.

Para os entrevistados, a atividade turística representa conhecer novas culturas (19\%) e viajar (15\%), apenas $2 \%$ acreditam que Turismo é praticar atividades relacionadas a estudos. A grande porcentagem referente a opção "viajar", demonstra a falta de visão e conhecimento dos entrevistados sobre as características e amplas possibilidades beneficiárias que o Turismo pode proporcionar para uma localidade.

Os entrevistadores puderam perceber em aplicação da pesquisa, que os entrevistados reconhecem a necessidade $e$ importância da atuação do profissional de Turismo (turismólogo) para o desenvolvimento da atividade turística, acreditando na educação de nível superior da atividade.

Os dados apresentados, reafirmam que o turismo pode trazer muitos benefícios para uma localidade, desde que haja conscientização por parte dos turistas, moradores locais e organizadores da atividade na localidade.

O planejamento é, portanto, um sistema circular em que as etapas vão 
se relacionando de forma dialética e dinâmica. O planejamento deve ser uma ação permanente de projetar, implantar, medir, reprojetar, reimplantar, medir de novo e assim sucessivamente". (IGNARRA, 2002, p. 69)

Para que esse planejamento seja alcançado, a participação do profissional da área de Turismo deve ser efetiva, já que este possui conhecimentos adequados, visão humanística, sistêmica e a longo prazo, possibilitando o desenvolvimento sustentável da atividade turística em uma localidade.

\section{Referências Bibliográficas}

DENCKER, Ada de Freitas Maneti. Métodos e Técnicas de Pesquisa em Turismo. 6.ed. São Paulo: Futura, 1998.

IGNARRA, Luiz Renato. Fundamentos do Turismo. 1.ed. São Paulo: Pioneira Thomson Learning, 2002.

RODRIGUES, Adyr Balastreri (org.). Turismo e desenvolvimento local. 3.ed. São Paulo: Hucitec, 2002.

TRIGO, Luiz Gonzaga Godoi. Turismo

Básico. 6.ed. São Pulo: Editora SENAC São

Paulo, 2002. 